\section{A Strategic Move}

The 1996 EPS Council took place at the Technical University, Lisbon, on 22-23 March.

"A somewhat special report" was how the President, H. Schopper, described his introduction to the 1996 EPS Council, for Council was to endorse the first ever Strategy Plan for EPS [see accompanying item] and agree to the Executive Committee proposal [EN 26 (1995) 133] that the Society base itself from 1 January next year in Mulhouse, France.

\section{A Strategy Plan for EPS}

The discussion that followed the President's presentation of the Strategy Plan, and implementation based on input from EPS bodies during the summer, confirmed the importance of having an agreed strategy that singled out the next generation of physicists as the key issue. For basic science is "facing new external conditions" and physics risks becoming an academic sideline in an era when research is a worldwide commodity and most of those who train as physicists will work outside physics (K.H. Chang, Utrecht). It was suggested that the Plan should therefore incorporate the notion of physics as an important and enabling science, and a special effort must be made to ensure a strong and viable implementation - something that tended to be difficult for learned societies. Areas outside physics in which physicists find employment should be spelt out and advice on how to access these opportunities generated (H. Kummer, Vienna), especially in medical and environmental physics where there are many possibilities (T. Henriksen, Oslo). Dissem-

\section{Research Strategies for Europe}

Promoting the importance of European Union (EU) support for basic research has become a vital issue, with most attention focused on the Union's next Framework Programme. K.H. Chang, the Director of The Netherlands' science funding agency FOM, speaking at the EPS Council felt that this effort risks becoming unfocussed since virtually every science-based organization in Europe is active. EPS must therefore define a dear strategy. J.E. Fenstad from 0slo, who chairs the European Science Foundation's (ESF) Standing Committee for Physical and Engineering Sciences (shown here on the left, with H.U. Karow, the ESF's Scientific Secretary for the Natural and Technical Sciences) explained in an invited presentation to Council that his committee aims to act as a platform to help the science and basic research communities develop arguments for the relevance of research. Long-range training in the context of the excellent scientific environment offered by facilities inating this information, and indeed general information about EPS, was vital (L. Samulesson, Linköping) and electronic means should be the priority (A. Bárány, Stockholm). National societies must be encouraged to incorporate the EPS strategy within their own plans (P.H. Melville, London). This would come about quite naturally if physicists from every country have the means to participate in EPS activities (D. Kiss, Budapest), which is not the case at present owing to financial constraints (J. Nadrchal, Prague); contacts with international organizations must also be strengthened (R.A. Ricci. Legnaro).

\section{The Move to Mulhouse}

Before Council, by a two-thirds majority of those present and voting, narrowly agreed to the proposed amendments to the EPS Constitution whereby the Society would be based in Mulhouse, the President reviewed the Mulhouse proposal. He first thanked the national societies that had made offers to host the EPS Secretariat. Mulhouse had been selected on the basis of apparently generous conditions made possible by the local authorities' wish to attract European organizations. The Budapest office would be closed down within two years and a future Secretary General, replacing $\mathrm{G}$. Thomas on his retirement in August 1997, would be engaged in 1996 and made responsible for building up a new Secretariat. The Europhysics Letters partnership had decided to keep the journal's editorial office in Geneva for the time

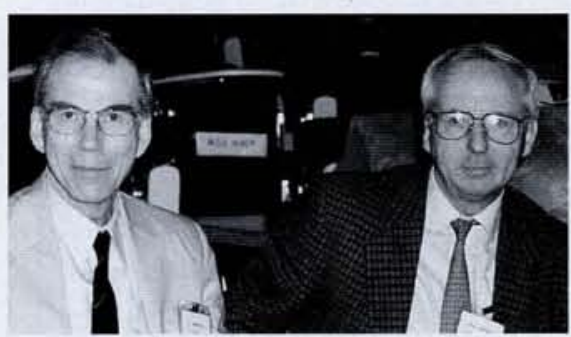

is a vital ingredient, so the ESF wants to create a clearing house to review proposals for facilities. In reinforcing links within the scientific community, this role would help build the vital broadly based consensus needed to launch a new facility. Another ESF goal is to secure more support for research from outside the EU's Training and Mobility of Researchers programme. According to D.L. Weaire (Dublin), who was elected as the EPS PresidentElect by Council, science now expects too much from the programme, which has moved to centre stage for science. being so the office would be separated from the Secretariat, thereby reducing considerably the impact on the Secretariat staff.

The Executive Committee was also proposing to change the unit fee from Swiss francs to the ECU to reduce the effect of the strong Swiss franc on the EPS budget and on members' fees. He was confident that cost reductions, modern management and the contracting out of tasks to national societies to reduce administrative overhead would allow greater support for activities, improved complementarity with national activities, an effective contribution to important problems (notably employment for physicists), and increased opportunities for generating a greater appreciation by the general public of the importance of physics.

The President indicated that more discussion about the move in order to plan better links between the Secretariat and European organizations (K. Bethge, Frankfurt; R.A. Ricci) was inadvisable because there had already been a postponement. Mulhouse being not only within the European Union but also cheaper, and cheaper to visit, were important features (A.D.W. Jones, London), although they did not mean that the Society should not look beyond its traditional sources of funding for support.

The Secretary, J.-Ph. Ansermet (Lausanne) summarised the consequences of the move on the EPS part of the Secretariat staff (an equivalent of 3.2 people). The Secretary General and the Editor of Europhysics News would be based full-time in Mulhouse together with about two junior staff. J.L. Lewis (Malvern), the Treasurer, assured Council that the move would produce savings, beyond the period of the additional expenses. He could not produce figures because they depended on many factors, including how the new Secretary General wished to organize the Secretariat.

The audited accounts for 1995 , which Council approved, reflected a very satisfactory year largely owing to a special payment to Europhysics News by Springer Verlag and to a surplus on conference activities. After attributing $59 \mathrm{kSFR}$ to the Special Development Fund there was a surplus of $62.5 \mathrm{kSFR}$ which eliminated the accumulated deficit. Council also approved the 1996 budget that sees a surplus of 30 kSFR and support for a wide range of activities. A 1997 budget according to activities for greater transparency will be drawn up now that the Society's future base has been decided. 


\section{ECUs for the Unit Fee}

The Executive Committee's proposal to change the unit fee to $9.76 \mathrm{ECU}$, based on the prevailing SFR-ECU exchange rate, was discussed in depth. A fee of 9.1 ECU was finally voted, it having been agreed by a show of hands that any value below the proposed fee implied a reduction and thus required the support of three out of four votes cast, with only IOM and national society representatives voting. Rounding up to 10 ECU (O. Poulsen, Copenhagen) and a decrease to 8.80 ECU, based on the rate that prevailed when the new EPS Constitution came into force (V. Häselbarth, Bad Honnef), were proposed. A compromise would maintain the support for east and central Europe while reducing the impact of the strong Swiss franc (E. Jakeman, Malvern), given that averaging backwards in time made little sense (E. Osnes, Oslo), some adjustment for inflation was reasonable (C. Sébenne, Paris) and fixing a particular day was arbitrary (C. Matos Ferreira, Lisbon). Council also agreed with the President's proposal that the unit fee be reexamined once the impact of the move to Mulhouse had been assessed.

\section{Various Activities Highlighted}

The reports by representatives of the various EPS Boards and Committees highlighted Internet-based activities as a major area of interest. Several Divisions and Interdivisional Groups have launched WWW-based newsletters. EPS initiatives are managed by the Internet Coordination Group which has recently launched a scheme to improve links between national WWW sites at the institute and society levels. The Group received the go-ahead to explore the possibility of making Division and Group membership lists available via WWW.

Physics teaching will receive a major boost once the European Physics Education Network (EUPEN) is in place (C. Matos Ferreira, Chair, Physics Education) and it would be wise to incorporate EUPEN into the EPS strategy (O. Poulsen). However, obtaining further funding for the European Union (EU)-supported European Mobility Scheme for Physics Student (EMSPS) to cover every east and central European country was proving difficult (H. Ferdinande, Mobility Committee) and reducing costs by having the administration contracted out to a national society may help (I. Strzaltkowski, Warsaw). But the demand remained clear, especially since an impressive $70 \%$ of students moving within the scheme

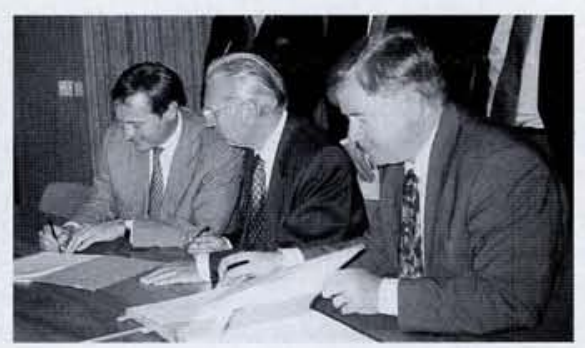

The EPS President, H. Schopper (seated in the middle), signing the framework agreement with J.-M. Bockel, Mayor of Mulhouse (left) and G. Prado, President of the Universite de Haute Alsace (right), that covers the establishment on 1 January 1997 of the EPS Secretariat at the Technopôle de la Mer Rouge on the outskirts of Mulhouse. The ceremony took place in Mulhouse on 29 May in the presence of representatives of the various local and regional authorities and organizations that are partners in the agreement.

have been able to transfer course credits to their home universities.

The very positive response to the launch of the Eur Phys designation clearly showed the needed for enhancing the professional recognition of individual physicists in modern economies (M. Peter, Chair, Register Commission). So it was important to help physicists from the economically weaker regions of Europe meet the cost of registering by scaling fees (P.H. Melville, Chair, Applied Physics and Physics in Industry) and having them in ECUs (G.C. Morrison, Birmingham), by establishing a solidarity fund once there was sufficient income, and by extending the registration period (J. Bessa Soussa, Porto) if this was compatible with the need to demonstrate satisfactory retraining. In the meantime, more information must be circulated via national societies, especially with regard to the impact of professional recognition on job opportunities (R. Morgenstern, Chair, Atomic and Molecular Physics). A proposal (P.H. Melville) to examine the possibility of having more than one physics-based EPS member society in a country, so that the scheme can be promoted more widely, was accepted.

The Solidarity Fund that supports participation at EPS conferences using a levy had set off to a good start with funds for 33 grants available this year (R. Pick, Chair, Conference Committee). But EUsupport had become more difficult to obtain since rules encouraged participation by young people while the reviewing of each European Research Conference (physics ERCs are proposed by Divisions) led to uncertainty about the ERC series.

Summaries of the decisions taken by Council (and by the Executive Committee that met on 21 March) were reported in News from EPS (March-April 1996). They can also be found on EurophysNet's europhysics news extra (http://epswww.epfl.ch)

\section{SEVILLE 1996}

EPS-10 General Conference Trends in Physics

Seville; 9-13 September 1996

- Many special meetings and events will take place in parallel with the General Conference.

- Fully updated details are given on the EPS EurophysNet WWW service (http://epswww.epfl.ch)

\section{A New Qualification for Physicists}

\section{Peter, Chair, Register Commission}

The designation European Physicist (abbreviated as Eur Phys) is a new qualification for physicists that was established by the EPS in 1995. The fundamental reason for its creation stems from the fact that times are changing, and are becoming harder for many physicists. Gone are the days when a permanent position is offered to most successful students upon graduation from university. Permanent employment may become the exception rather than the rule, so physicists, like most pro-

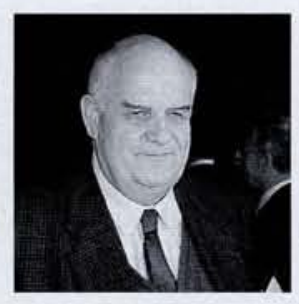

Martin Peter, the Chairman of the European Register of Physicists, is with the Physics Department, Geneva University. He has served as the Head of the Department and as the University's Rector. fessionals, have to reeducate, and to adapt to a new career more than once.

The reason for this evolution is to be found in the changing nature of the European economy, which is moving increasingly from the secondary sector into services. One might have hoped that this trend would increase rather than decrease research activities. To a certain extent this is indeed happening, but at the same time the nature of these activities is also changing since industrial research is tending to move to where manufacturing has gone.

In this changing climate, the possibility to adapt one's activities becomes an important asset. Adaptation includes continued education and the ability to take initiatives in organizing work for oneself and for others. It also includes mobility. Mobility is facilitated by professional qualifications which are widely recognised. 